\title{
Caracterização da cinza de caroço de açaí residual para adição ao concreto
}

\author{
Characterisation of residual açaí stone ash for addition to \\ concrete
}

\section{Luciana de Nazaré Pinheiro Cordeiro Isaura de Nazaré Lobato Paes \\ Paulo Sérgio Lima Souza Caroline Menezes Azevedo}

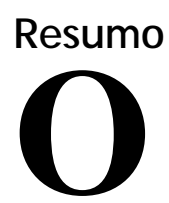

Assim, é interessante pensar em uma maneira de incorporar materiais que hoje são considerados resíduos ao processo construtivo e reduzir o consumo de materiais naturais. Nessa vertente, tem-se as cinzas de caroço de açaí, resíduo de fornos cerâmicos, que hoje não apresentam um destino adequado. Assim, esta pesquisa tem por objetivo principal caracterizar a cinza de caroço de açaí residual (CCAR), de modo a possibilitar seu reaproveitamento como insumo da construção civil. Para que esse objetivo seja alcançado realizou-se um estudo de moagem, de modo a determinar o tempo ótimo de beneficiamento do material, a caracterização do ponto de vista químico, físico e mineralógico e a análise do potencial pozolânico para avaliar a reatividade da cinza residual. Os resultados mostram que a cinza apresenta características físicas que permitem utilizá-la como adição ao concreto. Houve diminuição na resistência à compressão axial e aumento da absorção de água dos concretos com adições, em relação ao concreto de referência. Apesar desses efeitos, percebeu-se certa densificação da matriz cimentícia, provavelmente devido à variação do tamanho das partículas que podem vir a proporcionar maior compacidade com otimização do empacotamento dos grãos.

Palavras-chave: Cinza residual. Cinza do caroço de açaí. Pozolana.

\section{Abstract}

Environmental problems are a reality in today's world and are associated with urban and population growth, with little or no planning. The construction industry

${ }^{1}$ Luciana de Nazaré Pinheiro Cordeiro

${ }^{1}$ Universidade Federal do Pará Belém - PA - Brasil

${ }^{2}$ Isaura Nazaré Lobato Paes

2Universidade Federal do Pará Belém - PA - Brasil

${ }^{3}$ Paulo Sérgio Lima Souza

${ }^{3}$ Universidade Federal do Pará Belém - PA - Brasil

${ }^{4}$ Caroline Menezes Azevedo

4Universidade Federal do Pará Belém - PA - Brasil

Recebido em 06/12/16 Aceito em 24/04/18 is one of the largest consumers of natural resources and generator of solid waste.

Thus, it is interesting to think of a way to incorporate materials that are now considered waste, to the constructive process and reduce the consumption of natural materials. In this section, we have the ashes of açaí stone, residue of ceramic kilns, that today do not present an adequate destination. Thus, this research has the main objective to characterize residual ash of açaí (CCAR), in order to make possible its reuse as an input of the civil construction. In order to achieve this objective, a milling study was carried out in order to determine the optimum material processing time, characterization from the chemical, physical and mineralogical point of view, and the pozzolanic potential analysis to evaluate the residual ash reactivity. The results show that ash has physical characteristics that allow it to be used as an addition to concrete. There was a decrease in the axial compressive strength and an increase in the water absorption of concrete with additions, in relation to the reference concrete. In spite of these effects, a certain densification of the cementitious matrix was observed, probably due to the variation of the particle size that may provide greater compactness with optimization of grain packing.

Keywords: Residual ash. Açaí stone ash. Pozzolan. 


\section{Introdução}

A Política Nacional de Resíduos Sólidos (MINISTÉRIO..., 2015) estabelece que os agentes públicos e privados se responsabilizem pela destinação e reaproveitamento dos resíduos urbanos por eles gerados. A Lei $\mathrm{n}^{\circ} 12.305$ (BRASIL, 2010) prevê a elaboração de planos integrados de gerenciamento dos resíduos, e recomenda desenvolvimento nos sistemas de gestão voltado para a melhoria dos processos produtivos e ao aproveitamento de resíduos sólidos. Sendo assim, todo produtor deve preocupar-se com a qualidade do resíduo gerado, desenvolvendo planos de gestão em prol da sua melhoria e encaminhamento para um processo de desperdício nulo.

Nesse sentido, a indústria da construção civil tem capacidade de incorporar resíduos e subprodutos em vários de seus seguimentos, como, por exemplo, o emprego de cinzas e escórias na produção de cimentos, concretos e argamassas. Para que um resíduo possa se transformar em insumo da mencionada indústria, faz-se necessário avaliar sua viabilidade técnica, econômica e ambiental. Assim, intensificar os trabalhos que coloquem à disposição da construção civil materiais que contribuam para um desenvolvimento sustentável, mostra-se como uma solução viável aos pesquisadores. Quando o tema "reaproveitamento de resíduos em matrizes cimentícias" é fonte de pesquisas, sabe-se que a durabilidade desses compósitos, dentre eles o concreto, está diretamente ligada ao comportamento da rede de poros de seu interior, embora, explicitamente, entende-se que outras variantes têm que estar esclarecidas. Sob o ponto de vista da porosidade, o que realmente interessa para um concreto ser durável é a interconexão, o tamanho e a distribuição dos diâmetros dos poros (LUO et al., 2013; ZHAO et al., 2015).

Nesse sentido, a durabilidade do concreto pode ser incrementada com a introdução à sua composição de adições minerais ativas, ou seja, com propriedades pozolânicas. Alguns autores são unânimes em afirmar que entre as principais vantagens do uso dessas adições está a redução da porosidade e a maior proteção contra a penetração de alguns agentes agressivos, como, por exemplo, o cloreto e o sulfato (NAIK; SINGH, 1997; BARRINGER 1997; JONES; DHIR; MAGEE, 1997). Outros pesquisadores, como Ghrici e SaidMansour (2007), Belaidia, Azzouz e Kadri (2012) e Gameiro, Brito e Correia (2014), são enfáticos em assegurar que o emprego de adições, como: a sílica ativa, a cinza volante, a escória de alto forno, o metacaulim e outras, contribuem para o refinamento dos poros, o que resulta em uma diminuição do volume de vazios do concreto.
Atualmente, para se conseguir uma limitação da continuidade dos poros, há uma tendência de se adicionar, além das já consagradas adições pozolânicas, produtos inertes à composição dos cimentos, concretos e argamassas. Aitcin (1995) observou que a sílica ativa, que sabidamente é uma adição pozolânica, nos primeiros estágios de sua aplicação, em concretos e argamassas, atuava como inerte, ajudando a densificar a matriz da pasta. Esse efeito também foi observado por Belaidia, Azzouz e Kadri (2012), ao estudarem os efeitos de cimentos ternários nas propriedades de concretos autoadensáveis, nos estados fresco e endurecido. Haddadou et al. (2015), também avaliando as propriedades do concreto autoadensável com diferentes adições minerais e fibras, afirmaram que estudos de novas adições aos concretos são plenamente justificados, uma vez que estas podem vir a densificar a estrutura interna dos concretos, obstruindo a intercomunicabilidade dos poros e refletindo na melhora de sua durabilidade.

Nessa vertente, materiais provenientes da agroindústria também são avaliados para aplicação em matrizes cimentícias. Shafiq, Nuruddin e Elhameed (2014) avaliaram a implementação do bagaço da cana-de-açúcar na composição do concreto a fim de aumentar sua durabilidade frente ao ataque por sulfato. Já Aminudin et al. (2016) avaliaram o efeito da fibra e do óleo de palma para a melhoria do isolamento térmico das construções, ambos os trabalhos com resultados bastante promissores. Segundo os referidos autores, esses materiais têm despertado interesse devido a sua disponibilidade e sua composição química, que apresenta alto teor de sílica, fato que torna esses materiais uma fonte suplementar de adição mineral para a produção de materiais cimentícios.

Conforme colocado anteriormente, esta pesquisa tem por objetivo principal caracterizar a cinza de caroço de açaí residual, com vistas à possibilidade de reaproveitamento como insumo da indústria da construção civil. Para alcançar esse objetivo foi realizado um estudo de moagem, de modo a determinar o tempo ótimo de beneficiamento do material, a caracterização do ponto de vista químico, físico e mineralógico e a análise do potencial pozolânico para avaliar a reatividade da cinza residual.

\section{Materiais e métodos}

\section{Materiais}

Os materiais utilizados nesta pesquisa foram: cimento Portland CP II F-32, cimento Portland CP 
II Z-32 e hidróxido de cálcio. As massas específicas desses materiais foram determinadas pela NBR NM 23 (ABNT, 2012a) e resultaram em 3,07 g/ $\mathrm{cm}^{3}, 2,92$ $\mathrm{g} / \mathrm{cm}^{3}$ e $2,58 \mathrm{~g} / \mathrm{cm}^{3}$, respectivamente. Cabe ressaltar que o cimento CP II-Z-32 foi empregado somente na produção dos concretos, e o cimento Portland CP II-F-32 e o hidróxido de cálcio na mensuração da pozolanicidade da CCAR.

A areia segue os padrões indicados pela NBR 7214 (ABNT, 2012b), e trata-se de um agregado miúdo de origem quartzosa, comercialmente disponível na região metropolitana de Belém, que apresenta uma massa específica de 2,65 g/ $\mathrm{cm}^{3}$ e um diâmetro máximo de \#2,4 mm. Este tem dimensões em quatro faixas granulométricas de \#1,2 mm; \#0,6 mm; \#0,3 mm e \#0,15 mm, representando cada fração um percentual de $25 \%$ do material. A brita utilizada é de origem granítica de massa específica de 2,63 $\mathrm{g} / \mathrm{cm}^{3}$, massa unitária $1,53 \mathrm{~g} / \mathrm{cm}^{3}$, módulo de finura 6,85 e dimensão máxima característica de 25 mm.

O resíduo, proveniente da cinza residual do caroço do açaí, foi coletado em fornos de fábrica de cerâmicas localizadas no município de Castanhal, PA. Ressalta-se que o caroço de açaí passa inicialmente por um processo de secagem, em temperatura ambiente, para a retirada da umidade superficial e, em seguida, é colocado nos fornos em substituição a lenha. Esses fornos não apresentam controle de temperatura, gerando um resíduo de elevada heterogeneidade que, até o presente momento, não é reaproveitado na região. A água utilizada para a mistura das argamassas provém da Companhia de Saneamento do Pará (Cosanpa).

\section{Métodos}

\section{Beneficiamento da Cinza de Caroço de Açaí Residual (CCAR)}

A coleta da cinza de caroço de açaí residual seguiu as recomendações estabelecidas pela NBR 10007 (ABNT, 2004). A respeito do beneficiamento do material, a proposta inicial era utilizar o material no seu estado natural, sem nenhum beneficiamento. Contudo, sua heterogeneidade não permitiu esse tipo de utilização. A cominuição de materiais cimentícios e adições minerais é uma operação que se faz necessária para ativar as reações químicas. Quanto menor o tamanho da partícula, maior a superfície específica do material. Além disso, esse processo confere maior compacidade das misturas, pela redução da dimensão dos materiais. Sendo assim, optou-se por realizar a redução do tamanho das partículas em moinhos rotativos de bolas.

Para que esse processo fosse eficiente realizou-se um estudo de moagem, a fim de definir qual o tempo ótimo de beneficiamento, para atingir uma área superficial similar ou superior a do cimento.

A variante desse estudo foi o tempo de moagem, pré-estabelecidos em 1, 2, 3, 4 e 5 horas, e como variável de resposta adotou-se a finura pelo método de permeabilidade Blaine, seguindo as orientações da NBR 16372 (ABNT, 2015). A razão entre a carga dos corpos moedores e a quantidade de cinza obtida foi mantida constante, utilizando a proporção em massa, 3:1 (bolas:cinzas), conforme sugere os estudos de Pouey (2006).

\section{Caracterização da CCAR}

Após o processo de moagem foi realizada a caracterização física das amostras. Nessa etapa realizou-se os ensaios de massa específica, índice de finura e massa unitária, de acordo com a NBR NM 23 (ABNT, 2012a), NBR 11579 (ABNT, 2013) e NBR NM 45 (ABNT, 2006), respectivamente.

A caracterização química foi determinada pela técnica de espectrometria de fluorescência de raios $\mathrm{X}$ por dispersão de comprimento de onda. E a análise dos resultados foi baseada nas recomendações estabelecidas pela NBR 12653 (ABNT, 2016a).

A difratometria de raios $\mathrm{X}$ foi a técnica empregada para a caracterização mineralógica do resíduo. O equipamento utilizado foi um difratômetro que emite radiação $\mathrm{CuK} \alpha$ com intervalo de medida na faixa de $2^{\circ}$ a $72^{\circ}$ de $2 \theta$ e passo a cada 3 segundo de $0.02^{\circ}$. Essa análise foi realizada com o objetivo de verificar se as cinzas apresentavam fases cristalinas ou não, bem como identificar os minerais presentes nos resíduos. Para avaliação da morfologia da superfície do material utilizou-se a técnica microscopia eletrônica de varredura (MEV) por elétrons secundários. O objetivo principal desse ensaio foi analisar o formato e a textura das cinzas residuais.

\section{Avaliação da pozolanicidade da CCAR}

A pozolanicidade foi avaliada segundo as recomendações da NBR 5752 (ABNT, 2014) e NBR 5751 (ABNT, 2015c). A possível eficiência da cinza como material pozolânico foi avaliada pela relação entre as resistências da argamassa de referência e aquela com substituição parcial de cinza residual. A determinação de resistência à compressão axial seguiu as prescrições da NBR 7215 (ABNT, 1996).

\section{Avaliação da utilização da CCAR em concretos}

Para a avaliação do efeito da adição da CCAR no concreto foram formuladas 12 misturas, nas quais houve variação dos teores de adição (0\%, 5\%, 10\% 
e $15 \%)$ e das relações água/cimento $(0,45 ; 0,55$ e 0,65). As proporções de mistura encontram-se detalhadas na Tabela 1.

As misturas foram realizadas em betoneira de eixo inclinado com capacidade de 801 e rotação de 28 rpm, seguindo a ordem agregado graúdo, cimento, adição de CCAR, 50\% da água, agregado miúdo, o restante da água, e quando necessário aditivo redutor de água. Logo após a mistura realizou-se o ensaio de abatimento de tronco fixado em 100 \pm 20 $\mathrm{mm}$.

A resistência à compressão axial foi o parâmetro pelo qual se avaliou o desempenho mecânico do concreto com CCAR. Além dessa avaliação, também foi mensurada a absorção de água por capilaridade dos concretos produzidos com o resíduo. Para tal foram moldados sete corpos de prova cilíndricos de dimensões $(100$ x 200) mm para cada combinação, seguindo a prescrição da NBR 5738 (ABNT, 2016b). Aos 28 dias de idade quatro desses exemplares foram ensaiados à resistência à compressão axial (ABNT, 2007a) e nos outros três foi determinada a absorção de água por capilaridade (ABNT, 2012b). Os resultados foram tratados estatisticamente por meio da avaliação de média, desvio padrão, coeficiente de variação e análise de variância.

\section{Resultados e discussões}

\section{Beneficiamento da CCAR}

Na Tabela 2 estão os resultados de caracterização física das cinzas após o seu beneficiamento em moinho de bolas.

Nota-se que o tempo de moagem afetou nas características físicas do material de modo a alterar a sua finura e influenciar no empacotamento dos grãos. As características apresentadas da cinza residual foram massa específica de $2.400 \mathrm{~kg} / \mathrm{m}^{3}$ $2.700 \mathrm{~kg} / \mathrm{m}^{3}$ e massa unitária de $600 \mathrm{~kg} / \mathrm{m}^{3}$ a 1.000 $\mathrm{kg} / \mathrm{m}^{3}$. O ensaio de permeabilidade ao ar resultou em valores que ficaram no intervalo de $2.000 \mathrm{~cm}^{2} / \mathrm{g}$ a $5.000 \mathrm{~cm}^{2} / \mathrm{g}$. Assim como na pesquisa de Calheiro et al. (2016), observou-se que o tratamento de moagem afetou nos resultados de massa específica, de maneira que quanto maior o tempo, maior a massa das amostras. De modo geral os resíduos agroindustriais, tais como a cinza do bagaço de cana, cinza de casca de arroz, resíduo do tabaco e resíduo de madeira, são resíduos de menor densidade aparente (PRUTY; PATRO; BASARKAR, 2016). Esse baixo valor leva a um elevado volume de resíduo, que quando depositado ocupa grandes áreas de armazenamento.

Tabela 1 - Proporções de misturas com CCAR

\begin{tabular}{|c|c|c|c|c|c|c|c|}
\hline Misturas & $\mathbf{a} / \mathbf{c}$ & $\begin{array}{c}\text { Água } \\
\left(\mathrm{kg} / \mathrm{m}^{3}\right)\end{array}$ & $\begin{array}{c}\text { Cimento } \\
\left(\mathrm{kg} / \mathrm{m}^{3}\right)\end{array}$ & $\begin{array}{r}\text { CCAR } \\
\left(\mathrm{kg} / \mathrm{m}^{3}\right)\end{array}$ & $\begin{array}{c}\text { Agregado } \\
\text { miúdo }\left(\mathrm{kg} / \mathrm{m}^{3}\right)\end{array}$ & $\begin{array}{c}\text { Agregado } \\
\text { graúdo }\left(\mathrm{kg} / \mathrm{m}^{3}\right)\end{array}$ & $\begin{array}{c}\text { Aditivo } \\
\text { (\%) }\end{array}$ \\
\hline C0-45 & 0,45 & 168 & 373 & 0 & 768 & 1096 & 1 \\
\hline C0-55 & 0,55 & 198 & 359 & 0 & 740 & 1057 & 1 \\
\hline C0-65 & 0,65 & 226 & 347 & 0 & 715 & 1020 & 0 \\
\hline C5-45 & 0,45 & 168 & 373 & 19 & 768 & 1096 & 2 \\
\hline C5-55 & 0,55 & 198 & 359 & 18 & 740 & 1057 & 2 \\
\hline C5-65 & 0,65 & 226 & 347 & 17 & 715 & 1020 & 0 \\
\hline C10-45 & 0,45 & 168 & 373 & 37 & 768 & 1096 & 3 \\
\hline C10-55 & 0,55 & 198 & 359 & 36 & 740 & 1057 & 2 \\
\hline C10-65 & 0,65 & 226 & 347 & 35 & 715 & 1020 & 1 \\
\hline C15-45 & 0,45 & 168 & 373 & 56 & 768 & 1096 & 4 \\
\hline C15-55 & 0,55 & 198 & 359 & 54 & 740 & 1057 & 3 \\
\hline C15-65 & 0,65 & 226 & 347 & 52 & 715 & 1020 & 2 \\
\hline
\end{tabular}

Tabela 2 - Blaine obtidos pelos diferentes tempos de moagem

\begin{tabular}{|c|c|c|c|c|}
\hline $\begin{array}{c}\text { Tempo } \\
\text { (h) }\end{array}$ & $\begin{array}{c}\text { Blaine } \\
\left(\mathrm{cm}^{2} / \mathrm{g}\right)\end{array}$ & $\begin{array}{c}\text { Massa específica } \\
\left(\mathrm{kg} / \mathbf{m}^{3}\right)\end{array}$ & $\begin{array}{c}\text { Massa unitária } \\
\left(\mathrm{kg} / \mathrm{m}^{3}\right)\end{array}$ & $\begin{array}{c}\text { Índice de } \\
\text { vazios (\%) }\end{array}$ \\
\hline 1 & $4.358,02$ & 2540 & 663,30 & 74 \\
\hline 2 & $4.024,07$ & 2530 & 807,57 & 68 \\
\hline 3 & $4.648,26$ & 2660 & 923,59 & 65 \\
\hline 4 & $3.061,88$ & 2440 & 899,74 & 63 \\
\hline 5 & $2.396,18$ & 2700 & 932,66 & 66 \\
\hline
\end{tabular}


O propósito da moagem foi reduzir o tamanho das partículas empregando os equipamentos disponíveis na região. Segundo Pouey (2006) e Cordeiro (2009), a cominuição de materiais finos, por longos períodos, pode deixar de ser eficiente e passar a ser prejudicial ao material, uma vez que o aumento desse tempo pode levar a uma aglomeração dos finos no interior do moinho.

Neste trabalho, tempos superiores a 3 horas levaram à formação de conglomerados de partículas finas, resultando em maior área superficial e menor índice de vazios. Contudo, é interessante ressaltar que esse tempo pode ser diminuído, melhorando com isso a relação custo-benefício, desde que o moinho apresente maior eficiência. Essa situação foi constatada por Souza e Dal Molin (2005), quando da avaliação da moagem de argilas calcinadas em diferentes tipos de moinhos.

\section{Caracterização da CCAR}

A composição química da amostra de CCAR foi obtida por meio de fluorescência de raios $\mathrm{X}$ e do ensaio de perda ao fogo. Os valores obtidos estão apresentados na Tabela 3.

Pela análise química realizada percebe-se que os teores de sílica alcançados foram de $35,33 \%$, os teores de elementos reativos não alcançaram 50\% e a perda ao fogo foi de $14,53 \%$. Os teores de $\mathrm{K}_{2} \mathrm{O}$ e $\mathrm{N}_{2} \mathrm{O}$ foram, respectivamente, de $18,61 \%$ e $0,34 \%$.
Do ponto de vista da caracterização química, percebe-se que apesar da sílica ser o mineral predominante na composição química do resíduo da cinza de caroço de açaí, seus elementos reativos não atendem aos requisitos mínimos do somatório de óxidos que, segundo o prescrito na NBR 12653 (ABNT, 2016a), deve ser maior que 50\%. A mensuração da perda ao fogo, do mesmo modo, ultrapassou o valor máximo permitido de $10 \%$. Além disso, obteve-se uma quantidade expressiva de álcalis na CCAR: $18,61 \%$ de $\mathrm{K}_{2} \mathrm{O}$ e $0,34 \%$ de $\mathrm{N}_{2} \mathrm{O}$. Esses constituintes podem provocar a decomposição do concreto, visto que propiciam o aparecimento de reações deletérias, como, por exemplo, a reação álcali-agregado (NEVILLE, 2013). Analisando o teor de potássio em outras cinzas, tem-se que o encontrado na CCAR está muito elevado, quando comparado com a cinza de casca de arroz (3,60\%) e bagaço de cana-de-açúcar (9,02\%) (SENSALE, 2006, CORDEIRO; TOLEDO-FILHO; FAIRBAIRN, 2009). Contudo, é interessante ressaltar que os referidos teores podem apresentar variações decorrentes de solo e dos produtos empregados no seu cultivo. Como os estudos com esse tipo de resíduo ainda estão em processo inicial é evidente que outras análises químicas devam ser realizadas, para que os quantitativos desse tipo de material sejam catalogados.

Na Figura 1 está o difratograma de raios $\mathrm{X}$ da cinza de caroço de açaí gerada sem queima controlada.

Tabela 3 - Composição química das CCARs

\begin{tabular}{l|c|c|c|c|c|c|c|c|c}
\hline & $\mathrm{SiO}_{2}$ & $\mathrm{Al}_{2} \mathbf{O}_{3}$ & $\mathbf{F e}_{2} \mathbf{O}_{3}$ & $\mathbf{C a O}$ & $\mathbf{M g O}$ & $\mathbf{P}_{2} \mathbf{O}_{5}$ & $\mathbf{N a}_{2} \mathbf{O}$ & $\mathbf{K}_{2} \mathbf{O}$ & $\mathbf{P F}$ \\
\hline CCAR (\%) & 35,33 & 7,18 & 0,79 & 4,57 & 4,13 & 12,67 & 0,34 & 18,61 & 14,23 \\
\hline
\end{tabular}

\section{Figura 1 - Difratograma de Raios X da CCAR gerada pela queima do caroço de açaí}

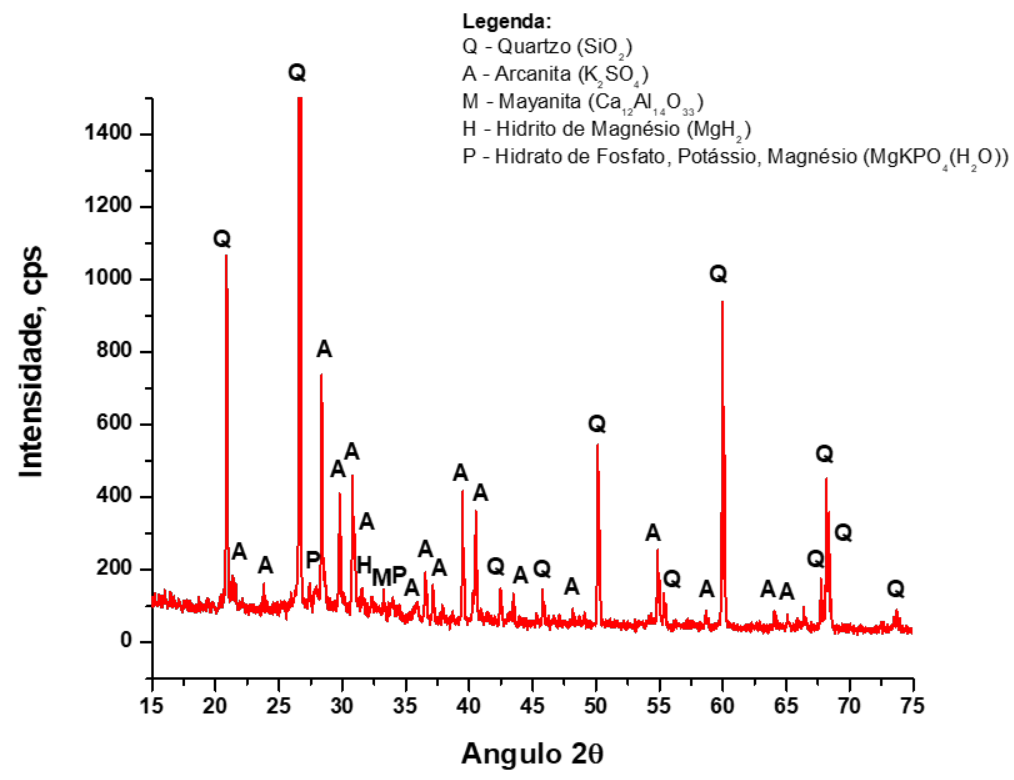


No que diz respeito ao difratograma de raios X, vêse que o material apresenta alguns picos cristalinos por meio do qual foi possível identificar minerais como o quartzo, potássio, hidreto de magnésio, hidrato de fosfato. Acredita-se que os dois últimos sejam decorrentes do processo de adubação do solo e do uso de fertilizantes que levou a contaminação deste resíduo (TEIXEIRA et al., 2004).

Com relação à sua micromorfologia, mostrada na Figura 2, percebe-se que a cinza residual apresenta um formato irregular, com algumas arestas bem definidas. Sua superfície apresenta certa rugosidade e irregularidades, o que pode ser consequência do processo de moagem empregado. Além disso, as imagens 2b e 2c evidenciam uma quantidade expressiva de vazios no material que pode gerar maior absorção de água por parte dos concretos com esse tipo de adição.

\section{Avaliação da pozolanicidade da CCAR}

Com relação ao ensaio de pozolanicidade da CCAR, obteve-se a resistência à compressão média, aos 28 dias, para o cimento de 28,2 MPa e para a cinza de 9,2 MPa. A partir desses resultados, determinou-se o índice de atividade pozolânica para o cimento. O valor mensurado foi $32 \%$ inferior ao limite estabelecido pela NBR 12653 (ABNT, 2016a). Com relação à quantidade de água requerida o valor obtido foi de $15 \%$ superior ao limite máximo de $10 \%$ permitido pela referida norma.

A respeito da determinação da atividade pozolânica com a cal, aos sete dias de idade, tem-se o valor médio de 2,0 $\mathrm{MPa}$ e um desvio de $3 \%$. O requisito físico encontrado não atende ao limite normativo de no mínimo $6 \mathrm{MPa}$. Dessa maneira, pode-se dizer que a cinza do caroço de açaí residual, analisada nesta pesquisa, não atende aos requisitos da norma supracitada.

Figura 2 - Microscopia eletrônica de varredura da CCAR com aproximação de: (a) $30 \mu \mathrm{m}$; (b) $10 \mu \mathrm{m}$; (c) $10 \mu \mathrm{m}$ e (d) $300 \mu \mathrm{m}$

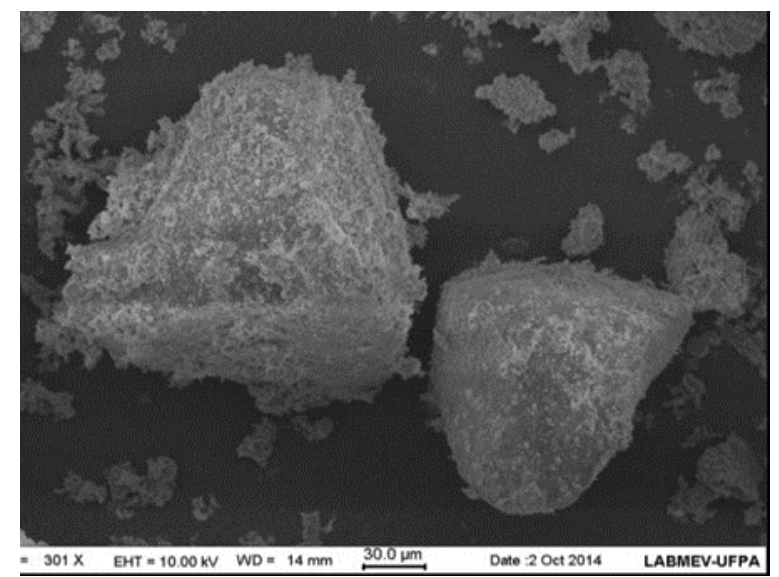

(a)

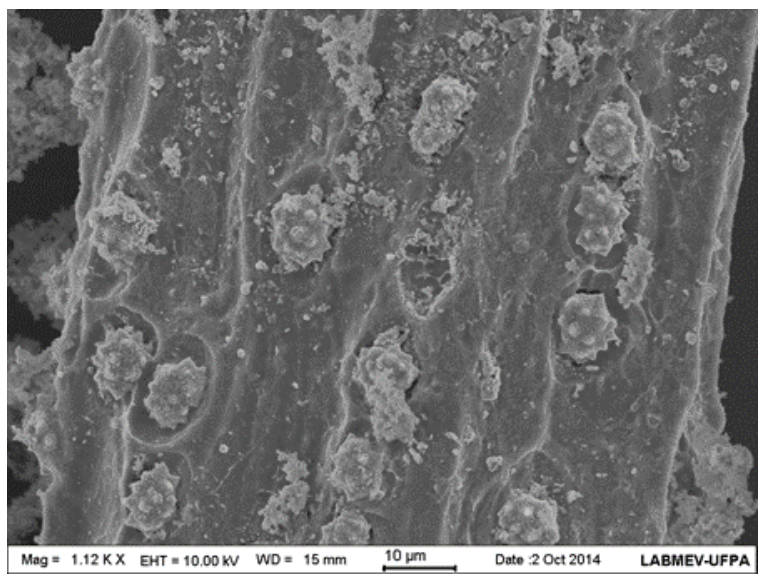

(C)

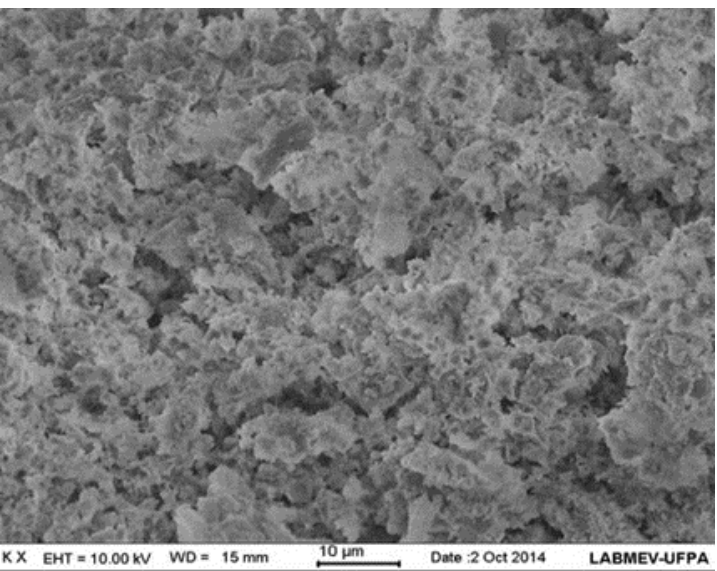

(b)

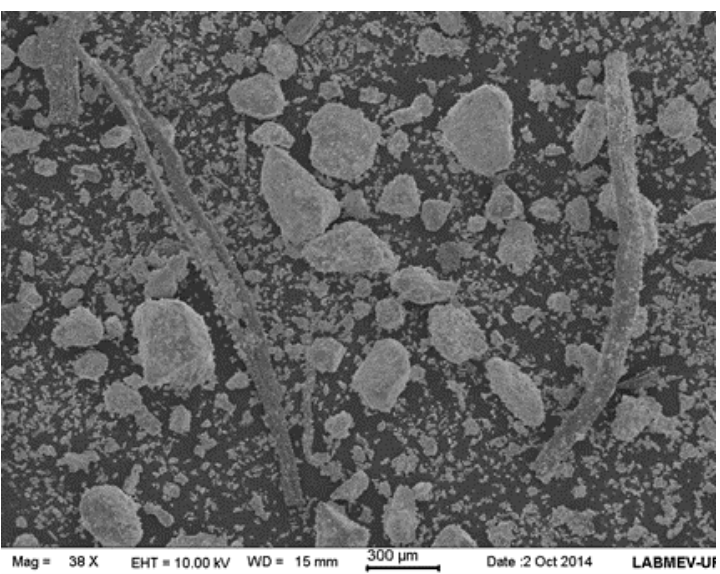

(d) 
No que se refere às exigências físicas, a norma aponta uma atividade pozolânica com o cimento de no mínimo 75\%, e aos 28 dias o valor alcançado foi $32 \%$ inferior. Para a cal o valor mínimo é de 6,0 Mpa. Mensurou-se 2,0 MPa. Logo, tendo como parâmetro os requisitos prescritos pela NBR 12653 (ABNT, 2016a), tem-se que o resíduo estudado não se apresenta como um material pozolânico.

Por outro lado, com o beneficiamento do resíduo a superfície específica Blaine e a massa unitária foram de $4.648,24 \mathrm{~cm}^{2} / \mathrm{g}$ e de $923,59 \mathrm{~kg} / \mathrm{m}^{3}$, respectivamente, para um tempo de moagem de 3 horas. Dessa forma, é possível que o emprego desse rejeito, nas condições atuais, proporcione uma ação física que otimiza o concreto produzido com essa adição. O formato dos grãos e/ou variação no tamanho das partículas normalmente proporcionam maior compacidade. Destefani e Holanda (2011) comentam que partículas mais finas de resíduos tendem a preencher os vazios entre as frações maiores, e assim otimizar o empacotamento dos grãos.

\section{Avaliação das propriedades mecânicas e da durabilidade}

Os resultados do ensaio de resistência à compressão axial dos concretos e absorção de água por capilaridade dos concretos com e sem adição de CCAR são apresentados na Tabela 4.

Os resultados mostraram que os concretos com adição de CCAR têm uma resistência à compressão axial inferior à do concreto de referência, produzido com cimento composto CPII Z. Embora nos concretos com resíduos tenha ocorrido um incremento de resistência com o aumento do teor de adição, esta não superou o patamar do concreto de referência. A CCAR, objeto de estudo desta pesquisa, apresenta estrutura cristalina e não atende aos requisitos químicos e físicos, estabelecidos pela NBR 12653 (ABNT, 2016a). A associação desses fatores justifica a baixa atividade pozolânica do compósito, colaborando dessa maneira para que o concreto com a CCAR não alcançasse o patamar de resistência do concreto de referência nas idades estudadas. No entanto, mesmo não atingindo o patamar de resistência da mistura de referência, constata-se que não houve diminuição expressiva nessa propriedade, uma vez que a variação foi de no máximo 20\% para os teores de substituição de 15\%. Logo as características físicas do material estão contribuindo para esse comportamento. Outro fator que poderia justificar a queda de resistência seria a característica microestrutural do resíduo, que se trata de uma estrutura porosa, com presença de matéria orgânica (perda ao fogo de 14\%), decorrente da ineficiência da queima na eliminação do material orgânico que elevou a taxa de absorção e prejudicou o seu desempenho final, em virtude da falta de tratamento térmico sem controle. Kuo et al. (2013) examinaram o comportamento de concretos com ostras, em que houve uma diminuição da resistência devido principalmente à característica microestrutural do material que elevou sua taxa de absorção. Esse fato pode ser observado pelos ensaios de absorção de água por capilaridade em que se percebe que a CCAR no concreto promove aumento na capacidade de absorção quando comparado com o de referência. Na família de 0,45, por exemplo, aos 91 dias o concreto com $10 \%$ de CCAR apresentou uma absorção 56\% superior à do concreto de referência.

Tabela 4 - Resultados médios de resistência à compressão axial e absorção de água por capilaridade

\begin{tabular}{c|c|c|c|c}
\hline \multirow{2}{*}{ Notação } & \multicolumn{2}{|c|}{ Resistência à compressão (MPa) } & \multicolumn{2}{c}{ Absorção por capilaridade (g/cm²) } \\
\cline { 2 - 5 } & $\mathbf{2 8}$ dias & $\mathbf{9 1}$ dias & $\mathbf{2 8}$ dias & $\mathbf{9 1 ~ d i a s ~}$ \\
\hline C0-45 & $45,8 \pm 0,6$ & $65,1 \pm 1,9$ & $0,50 \pm 0,04$ & $0,43 \pm 0,01$ \\
C0-55 & $26,3 \pm 0,3$ & $29,9 \pm 2,0$ & $0,72 \pm 0,08$ & $0,42 \pm 0,01$ \\
C0-65 & $21,3 \pm 0,5$ & $34,6 \pm 0,9$ & $1,03 \pm 0,08$ & $0,42 \pm 0,03$ \\
C5-45 & $49,6 \pm 0,8$ & $43,4 \pm 2,1$ & $0,30 \pm 0,04$ & $0,62 \pm 0,04$ \\
C5-55 & $23,6 \pm 1,2$ & $37,6 \pm 1,9$ & $0,62 \pm 0,02$ & $0,97 \pm 0,02$ \\
C5-65 & $20,9 \pm 1,2$ & $27,3 \pm 0,9$ & $0,74 \pm 0,04$ & $1,32 \pm 0,12$ \\
C10-45 & $42,1 \pm 1,0$ & $52,2 \pm 1,7$ & $0,85 \pm 0,02$ & $0,67 \pm 0,04$ \\
C10-55 & $31,2 \pm 0,8$ & $35,7 \pm 1,8$ & $0,58 \pm 0,06$ & $0,65 \pm 0,04$ \\
C10-65 & $19,3 \pm 0,6$ & $26,7 \pm 0,7$ & $0,60 \pm 0,06$ & $0,77 \pm 0,05$ \\
C15-45 & $40,0 \pm 0,6$ & $53,9 \pm 1,4$ & $0,56 \pm 0,07$ & $0,44 \pm 0,02$ \\
C15-55 & $35,9 \pm 0,7$ & $39,4 \pm 1,1$ & $0,81 \pm 0,06$ & $0,55 \pm 0,02$ \\
C15-65 & $25,6 \pm 1,5$ & $23,3 \pm 0,5$ & $0,93 \pm 0,07$ & $0,79 \pm 0,06$ \\
\hline
\end{tabular}


Diversas pesquisas abordam o uso de resíduos agrícolas em concreto e os resultados são satisfatórios no que tange à resistência mecânica, uma vez que os valores em geral se equiparam ou superam o concreto de referência (ISAIA et al., 2010; MODANI; VYAWAHARE, 2013; SHAH et al., 2014; ATAIE, RIDING, 2016). Esses autores atribuem esse desempenho à progressão das reações pozolânicas, comum em resíduos agrícolas, como a cinza de casca de arroz e a cinza de bagaço de cana. No entanto, para que essas reações ocorram o material deve apresentar elevado teor de $\mathrm{SiO}_{2}$ na condição amorfa e elevada finura, pois a associação desses parâmetros leva a um efeito sinergético, se dispersado homogeneamente na matriz cimentícia (LE; LUDWIG, 2016).

Observa-se pelos valores baixos de desvio padrão $(0,01-2,1)$ a pequena variabilidade dos resultados. Em cada mistura ensaiada aos 28 dias é possível identificar que pelo menos uma combinação do concreto com adição de CCAR promove um incremento de resistência. Na família 0,65 a mistura C15-65 foi maior em $17 \%$ que o concreto referência (C0-65). Na família 0,55 as misturas C10-55 e C1555 obtiveram um incremento de resistência em comparação com a referência de 19\% e 37\%, respectivamente. Já na família 0,45 apenas a mistura C5-45 superou o concreto referência em 8\%. Quando analisadas aos 91 dias nota-se que somente para a família de 0,55 a resistência do concreto com adição de CCAR ultrapassou a da referência em seus diferentes teores. Porém, os valores alcançados em todas as misturas são expressivos e englobam a faixa de resistência $20 \mathrm{MPa}$ - $50 \mathrm{MPa}$.

Atribui-se os ganhos de resistência decorrente do aumento de teor de adição ao efeito físico do material fino, que pode ter levado a uma densificação da microestrutura. Acredita-se, porém, que o equipamento disponível para moagem não se mostrou eficiente, uma vez que para se obter uma área superficial inferior à do cimento foi necessária uma moagem em tempos muito longo (3 horas), que demandou elevado gasto energético, mas que se fez necessário, pois era o que se tinha disponível na região. Mageswari e Vidivelli (2009), Sada, Amartey e Bakoc (2013) e Kuo et al. (2013) examinaram o efeito de resíduos não pozolânicos no concreto e para alguns experimentos o material também não foi capaz de superar o concreto de referência, uma vez que é preciso ter sinergia entre as características do material e o processo de mistura para que os resultados sejam favoráveis. Esses indícios levam a crer que a cinza na sua forma residual deve ser usada com cautela em elementos estruturais que sejam expostos à água e/ou a outro agente agressivo, visto que apesar de alcançarem valores superiores a $30 \mathrm{MPa}$, que seria tecnicamente aceitável para fins estruturais, apresentam maior absorção em relação ao concreto de referência, sem a incorporação de CCAR.

\section{Conclusões}

Pelo presente trabalho conclui-se que as cinzas de caroço de açaí residual apresentam características físicas que permitem sua utilização como adição não reativa. No entanto, faz-se necessário cautela, bem como estudos complementares a fim de otimizar o desempenho desse material em compósitos cimentícios visando a sua durabilidade.

No que tange à caracterização pozolânica notou-se que a CCAR não atendeu aos parâmetros normativos estabelecidos pela NBR 12653 (ABNT, 2016a). A respeito dos componentes químicos e mineralógicos não foram detectados minerais reativos, porém recomenda-se que testes complementares sejam realizados. Do ponto de vista de desempenho mecânico do concreto notouse aumento na resistência à compressão pela incorporação de adição, para algumas famílias, porém esse incremento não foi suficiente para superar o patamar de resistência dos concretos de referência em idades avançadas. A provável justificativa para tal efeito seria a densificação da microestrutura pela presença do material fino. Porém, foi constatado aumento na capacidade de absorção de água, situação que pode estar relacionada às características morfológicas da cinza residual que apresenta uma estrutura visualmente porosa, rugosa, e com partículas irregulares.

Com relação ao beneficiamento adotado para a cominuição do resíduo, constata-se que três horas de moagem não é um tempo aceitável em termos práticos, visto que há elevado gasto energético. No entanto, o equipamento disponível no laboratório apresentava essa limitação, e o aumento da área superficial do material só foi atendida nessas condições. Em um equipamento de maior potência e energia de rotação, o resultado possivelmente seria obtido em um tempo menor.

\section{Referências}

AITCIN, P. C. 120 MPa Sem Mistério. Téchne, v. 19, p. 29-33, 1995.
AMINUDIN E. et al. Properties of Agro-
Industrial Aerated Concrete as Potential
Thermal Insulation for Building. Owned by the authors, published by MATEC Web of Conferences, 47, 2016. Disponível em: $<$ https://www.matec- conferences.org/articles/matecconf/abs/2016/10/m atecconf_iconcees2016_04020/matecconf_iconcee s2016_04020.html>. Access on: 15 out. 2017. 
ASSOCIAÇÃO BRASILEIRA DE NORMAS TÉCNICAS. NBR 10007: amostragem de Resíduos Sólidos. Rio de Janeiro, 2004.

ASSOCIAÇÃO BRASILEIRA DE NORMAS TÉCNICAS. NBR 11579: cimento Portland: determinação do índice de finura por meio da peneira $75 \mu \mathrm{m}$ (n $\left.{ }^{\circ} 200\right)$. Rio de Janeiro, 2013.

ASSOCIAÇÃO BRASILEIRA DE NORMAS TÉCNICAS. NBR 12653: materiais pozolânicos: requisitos. Rio de Janeiro, 2016a.

\section{ASSOCIAÇÃO BRASILEIRA DE NORMAS} TÉCNICAS. NBR 16372: cimento Portland e outros materiais em pó: determinação da finura pelo método de permeabilidade ao ar (método de Blaine). Rio de Janeiro, 2015.

\section{ASSOCIAÇÃO BRASILEIRA DE NORMAS}

TÉCNICAS. NBR 5738: concreto: procedimento para moldagem e cura de corpos de prova. Rio de Janeiro, 2016b.

\section{ASSOCIAÇÃO BRASILEIRA DE NORMAS}

TÉCNICAS. NBR 5739: concreto: ensaio de compressão de corpos de provas cilíndricos. Rio de Janeiro, 2007a.

\section{ASSOCIAÇÃO BRASILEIRA DE NORMAS}

TÉCNICAS. NBR 5751: materiais pozolânicos: determinação da atividade pozolânica: índice de atividade pozolânica com cal: método de ensaio. Rio de Janeiro, 2012c.

\section{ASSOCIAÇÃO BRASILEIRA DE NORMAS}

TÉCNICAS. NBR 5752: materiais pozolânicos: determinação de atividade pozolânica com cimento Portland: índice de atividade pozolânica com cimento: método de ensaio. Rio de Janeiro, 2014.

\section{ASSOCIAÇÃO BRASILEIRA DE NORMAS} TÉCNICAS. NBR 7214: areia normal para ensaio de cimento: especificação. Rio de Janeiro, 2012b.

\section{ASSOCIAÇÃO BRASILEIRA DE NORMAS} TÉCNICAS. NBR 7215: cimento Portland: determinação da resistência à compressão. Rio de Janeiro, 1996.

\section{ASSOCIAÇÃO BRASILEIRA DE NORMAS} TÉCNICAS. NBR 9779: argamassa e concretos endurecidos: determinação da absorção por capilaridade. Rio de Janeiro, 2007b.

\section{ASSOCIAÇÃO BRASILEIRA DE NORMAS} TÉCNICAS. NBR NM 23: cimento Portland e outros materiais em pó: determinação da massa específica. Rio de Janeiro, 2012a.

\section{ASSOCIAÇÃO BRASILEIRA DE NORMAS TÉCNICAS. NBR NM 45: agregados:} determinação da massa unitária e do volume de vazios. Rio de Janeiro, 2006.
ATAIE, F. F.; RIDING, K. L. Influence of Agricultural Residue Ash on Early Cement Hydration and Chemical Admixtures Adsorption. Construction and Building Materials, v. 106, p. 274-281, 2016.

BARRINGER, W. L. Before Using Flay ash. Concrete International, Michigan, v. 19, n. 4, apr. 1997.

BELAIDIA. S. E., AZZOUZ L, KADRI E. Effect of Natural Pozzolana and Marble Powder on the Properties of Self-Compacting Concrete.

Construction and Building Materials, v. 31: 251-257, 2012.

BRASIL. Lei 12.305 de 02 de agosto de 2010, que institui a Política Nacional de Resíduos Sólidos e altera a Lei n. 9.605, de 12 de fevereiro de 1998; e dá outras providências. DF, Brasília, Planalto, Casa Civil, 2010a. Disponível em: http://www.mma.gov.br/port/conama/legiabre.cfm ?codlegi=636. Acesso em: 29 maio 2015. 16:00h.

CALHEIRO, D. et al. Influência da Segregação Granulométrica e do Emprego de Aditivos de Moagem na Adequação de Cinzas de Casca de Arroz Como Coproduto. Revista Matéria, v. 21, p. 270-281, 2016.

CORDEIRO, G. C. Analise da Variação do Índice de Amorfismo da Cinza de Casca de Arroz Sobre a Atividade Pozolânica. Porto Alegre, 2009. Dissertação (Mestrado em Engenharia Civil) - Escola de Engenharia, Universidade Federal do Rio Grande do Sul, 2009.

CORDEIRO, G.C; TOLEDO FILHO, R. D; FAIRBAIRN, E. M. R. Caracterização de Cinza do Bagaço de Cana-de-Açúcar Para Emprego Como Pozolana em Materiais Cimentícios. Química Nova, São Paulo, v. 32, n. 1, 2009.

DESTEFANI, A. Z; HOLANDA, J. N. F. Utilização do Planejamento Experimental em Rede Simplex no Estudo de Resíduo de Rocha Ornamental Como Filler Para Obtenção de Máxima Compacidade. Cerâmica, v. 57, 2011.

GAMEIRO, F.; BRITO, J.; CORREIA, S. D. Durability Performance of Structural concrete Containing Fine Aggregates from Waste Generated by Marble Quarrying Industry. Engineering Structures, v. 59, p. 654-662, 2014.

GHRICI M, K. S.; SAID-MANSOUR, M.

Mechanical Properties and Durability of Mortar and Concrete Containing Natural Pozzolana and Limestone Blended Cements. Cement and Concrete Compósites, v. 29, p. 542-549, 2007. 
HADDADOU, N. et al. Fresh and Hardened Properties of Self-Compacting Concrete With Different Mineral Additions and Fibers. Journal of Building Materials and Structures, v. 2, p. 41-50, 2015.

ISAIA, G. C. et al. Viabilidade do Emprego de Cinza de Casca de Arroz Natural em Concreto Estrutural: parte 1: propriedades mecânicas e microestrutura. Ambiente Construído, Porto Alegre, v. 10, n. 1, p. 121-137, jan./mar. 2010.

JONES, M. R.; DHIR, R. K.; MAGEE, B. J. Concrete Containing Ternary Blended Binders: resistence to chloride ingress and carbonation, Cement and Concrete Research, New York, v. 27, n. 6, p. 825-831, jun. 1997.

KUO, W. T. et al. Engineering Properties of Controlled Low-Strength Materials Containing Waste Oyster Shells. Construction and Building Materials, v. 46, p. 128-133, 2013.

LE, H. T.; LUDWIG, H. M. Effect of Rice Husk Ash and Other Mineral Admixtures on Properties of Self-Compacting High Performance Concrete. Materials and Design, v. 89, p. 156-166, 2016.

LUO F. J. et al. Effect of Very Fine Particles on Workability and Strength of Concrete Made With Dune Sand. Construction and Building Materials, v. 47, p. 131-137, 2013.

MAGESWARI, M.; VIDIVELLI, B. The Use of Saw Dust Ash as Fine Aggregate Replacement in Concrete. Journal of Environmental Research and Development, v. 3, p. 720-726, 2009.

MINISTÉRIO DO MEIO AMBIENTE. Plano Nacional de Resíduos Sólidos. Disponível em: <http://www.mma.gov.br/estruturas/253/_publicac ao/253_publicacao02022012041757.pdf>. Acesso em: 29 maio 2015.

MODANI, P.; VYWAHARE, M. R. Utilization of Bagasse Ash as a Partial Replacement of Fine Aggregate in Concrete. Procedia Engineering, v. 51, p. 25-29, 2013.

NAIK, T. R.; SINGH, S. S. Influence of Flay Ash on Setting and Hardening Characteristics of Concrete Systems. ACI Materials Journal, Michigan, v. 94, n. 5, sept./oct. 1997.

NEVILLE, A. M. Propriedades do Concreto. 2. Ed. Porto Alegre: Bookman, 2013.
POUEY, M. T. F. Beneficiamento da Cinza de Casca de Arroz Residual Com Vistas à Produção de Cimento Composto e/ou Pozolânico. Porto Alegre, 2006. Tese (Doutorado em Engenharia Civil) - Escola de Engenharia, Universidade Federal do Rio Grande do Sul, Porto Alegre, 2006.

PRUSTY, J. K.; PATRO, S. K.; BASARKAR, S. S. Concrete Using Agro-Waste as Fine Aggregate For Sustainable Built Environment: a review. International Journal of Sustainable Built Environment, v. 5, p. 312-333, 2016.

SADA, B. H.; AMARTEY, Y. D.; BAKOC, S. An Investigation Into the Use of Groundnut Shell as Fine Aggregate Replacement. Nigerian Journal of Technology, v. 32, p. 54-60, 2013.

SENSALE, G. R. B. Strength Development of Concrete With Rice-Husk Ash. Cement and Concrete Composites, v. 28, p. 158-160, 2006.

SHAFIQ, N.; NURUDDIN, M. F.; ELHAMEED, A. A. Effect of Sugar Cane Bagasse Ash (SCBA) on Sulphate Resistance of Concrete. International Journal of Enhanced Research in Science Technology \& Engineering, v. 3, p. 64-67, 2014.

SHAH, P. A. et al. Sugarcane Baggase Ash and Pozzocrete as an Technoeconomical Solution in Design Mix Concrete. Indian Journal Applied Research, v. 4, p. 243-245, 2014.

SOUZA, P. S. L.; DAL MOLIN, D. C. C. Viability of Using Calcined Clays, From Industrial byProducts, as Pozzolans of High Reactivity. Cement and Concrete Research, v. 35, p. 19931998, 2005.

TEIXEIRA, L. B. et al. Características Químicas de Composto Orgânico Produzido Com Lixo Orgânico, Caroço de Açaí, Capim e Serragem. Belém: Embrapa Amazônia Oriental, 2004. (Embrapa Amazônia Oriental. Comunicado Técnico, 105).

ZHAO, J. et al. Ultra Fine Grinding of Fly Ash With Grinding Aids: impact on particle characteristics of ultrafine fly ash and properties of blended cement containing ultrafine fly ash. Construction and Building Materials, v. 78, p. 250-259, 2015. 


\section{Luciana de Nazaré Pinheiro Cordeiro}

Faculdade de Engenharia Civil, Instituto Tecnológico | Universidade Federal do Pará | Rua Augusto Correa, 1, Guamá | Belém - PA - Brasil | CEP 66075-110 | Tel.: (91) 3201-7917 | E-mail: lucianapc@ufpa.br

\section{Isaura Nazaré Lobato Paes}

Faculdade de Engenharia Civil, Instituto Tecnológico | Universidade Federal do Pará | E-mail: isaurapaes@ufpa.br

\section{Paulo Sérgio Lima Souza}

Faculdade de Engenharia Civil, Instituto Tecnológico | Universidade Federal do Pará | E-mail: paseliso@ufpa.br

\section{Caroline Menezes Azevedo}

Faculdade de Engenharia Civil, Instituto Tecnológico | Universidade Federal do Pará | Tel.: (91) 3243-6634 | E-mail:

carolinemenezes1@ive.com

\section{Revista Ambiente Construído}

Associação Nacional de Tecnologia do Ambiente Construído

Av. Osvaldo Aranha, 99 - 3o andar, Centro

Porto Alegre - RS - Brasil

$$
\text { CEP 90035-190 }
$$

Telefone: +55 (51) 3308-4084

Fax: +55 (51) 3308-4054

www. seer. ufrgs. br/ ambienteconstruido

E-mail: ambienteconstruido@ufrgs.br 